\title{
Hydrothermally treated cement-based building materials. Past, present, and future*
}

\author{
A. Ray ${ }^{\ddagger}$ \\ Department of Chemistry, Materials and Forensic Science, Faculty of Science, \\ University of Technology, Sydney, Australia
}

\begin{abstract}
Hydrothermally cured or autoclaved cement-based building products have provided many challenges to researchers, manufacturers, and users since their inception nearly 100 years ago. The advantages, including the development of high strength within a few hours and a reduction of drying shrinkage, of the hydrothermal curing process have resulted in a variety of building products; inevitably, the technology of their production has undergone many stages of refinement. With the advent of nonconventional starting materials for the production of modern cements, and the push to utilize renewable resources to form blended cements, the chemical and physical make-up of hydrothermally cured building materials have changed considerably in recent years and will continue to change. It is, therefore, important to understand the chemical reactions taking place in an autoclave, and the consequent phase developments, if building materials produced by this process continue to be successful in the long term. A wide range of analytical techniques exists for characterizing the phase development in cement-based materials. The purpose of this paper is to illustrate the strength of thermal methods, especially when used in combination with other analytical techniques, in the understanding of hydrothermal reactions.
\end{abstract}

\section{INTRODUCTION}

Cement-based building materials are well known for their durability. The relatively easy availability of raw materials and continuous improvement in production methods have contributed to the success that these traditional materials have enjoyed worldwide. In recent years, however, the environmental awareness of society has generated considerable interest in the economical use of both naturally occurring raw materials and the energy for their production. New ideas on the utilization of recyclable resources and the production of new-generation cements are attracting the attention of manufacturers of building products and support from governments in many parts of the world. The current interest lies not only in the application of useful ideas but also in the manufacturing process by which nontraditional starting materials can be combined to produce desirable building materials. In this regard, hydrothermal curing is of special interest to academic researchers as well as industrial manufacturers of cement-based building materials.

Hydrothermal curing or autoclaving process is used extensively to produce a wide range of cement-based materials including dense concretes, lightweight or aerated concretes (AAC), thermal insulation boards, and fiber-reinforced cement products [1]. This method of manufacture provides several advantages over the air-curing method in the manufacturing of cement-based building products. Autoclaving increases the rate of cement hydration under steam pressure considerably with the prod-

\footnotetext{
*Lecture presented at the $5^{\text {th }}$ Conference on Solid State Chemistry (SSC 2002), Bratislava, Slovakia, 7-12 July 2002. Other presentations are published in this issue, pp. 2083-2168.

*E-mail: A.Ray@uts.edu.au
} 
ucts reaching high strength in a matter of a few hours in comparison with the 28-day strength of aircured products [2]. Indeed, Lutter [3] concluded “...the environmentally minded consumer should use autoclaved building materials whenever possible", following his investigation of the primary energy content of building materials.

Typically for cement-based building materials, a mixture of Portland cement and/or lime, and finely ground siliceous raw materials such as quartz sand, is cured at temperatures between 160 and $200{ }^{\circ} \mathrm{C}$ under saturated steam pressure for several hours. A landmark study by Kalousek and Adams [4] initiated the understanding of the chemistry of hydrothermal processes related to the cement-based systems. The phases formed at the completion of the hydrothermal treatment depend largely on the starting materials used. The knowledge of phase evolution, crystalline or otherwise, and the resultant microstructure is critical from the viewpoint of the durability of the product. For instance, 1.1-nm tobermorite, a hydrous calcium silicate formed under hydrothermal conditions, is regarded as one of the primary contributors to the strength of the cement and/or lime-based products. With respect to the characterization of phases formed from autoclaving of cement-based materials, thermal analytical methods have been highly successful for nearly half a century [5].

This article focuses on the hydrothermally cured $\mathrm{CaO}-\mathrm{Al}_{2} \mathrm{O}_{3}-\mathrm{SiO}_{2}-\mathrm{H}_{2} \mathrm{O}$ system, which is relevant in relation to commercially manufactured cement-based building products. It is aimed at highlighting the role played by thermal analysis (TA) in characterizing the phase evolution and monitoring the phase assemblage during the hydrothermal process. Only selected examples are cited due to the large volume of published data available in literature. The future of TA and its potential use are briefly discussed in the context of a new generation of starting materials in autoclaved cement-based building products. Conventional cement chemistry notations $\left(\mathrm{C}=\mathrm{CaO}, \mathrm{A}=\mathrm{Al}_{2} \mathrm{O}_{3}, \mathrm{~S}=\mathrm{SiO}_{2}\right.$, and $\left.\mathrm{H}=\mathrm{H}_{2} \mathrm{O}\right)$ have been used throughout the text.

\section{PHASE CHARACTERIZATION AND THERMAL ANALYSIS}

In calcium silicate-based building products, calcium silicate hydrates $(\mathrm{C}-\mathrm{S}-\mathrm{H})$ of the tobermorite group constitute the principal binding agent. Members of the tobermorite group have a range of composition and vary in their degree of crystallinity. Hydrogarnet, a member of the $\mathrm{C}_{3} \mathrm{AS}_{3-x} \mathrm{H}_{2 x}$ series, is another important phase in hydrothermally treated $\mathrm{CaO}-\mathrm{Al}_{2} \mathrm{O}_{3}-\mathrm{SiO}_{2}-\mathrm{H}_{2} \mathrm{O}$ system. These two phases, in particular the Al-tobermorite and Si-hydrogarnet variety, are considered as critical phases in relation to the durability of autoclaved building products of this system [6-9]. Accurate identification and proof of coexistence of these critical phases is, therefore, a priority for analysts.

TA, which is one of the oldest analytical methods used in the study of cementitious materials, has played a significant role in the characterization and quantification of phases formed. TA includes many techniques of which differential thermal analysis (DTA), thermogravimetry (TG), differential scanning calorimetry (DSC), and thermomechanical analysis (TMA) are commonly employed in the characterization of cement-based materials. Reviews in literature including those by Ramachandran [10], Mackenzie [11], Ben-Dor [12], Bhatty [13], and Klimesch and Ray [14] have comprehensively covered the interpretations of TA in cement chemistry. TA is widely used in cement science because of its many advantages. For instance, the amount of sample necessary for analysis is small $(<50 \mu \mathrm{g})$, duration of experimentation is fast, and both amorphous and crystalline phases can be detected. These advantages are particularly important in academic study as well as in industrial research where routine analysis and trouble shooting are integral to quality control. Furthermore, simultaneous thermal methods are able to provide complementary information and differentiation of overlapping thermal events. A comprehensive coverage of simultaneous techniques and product analysis has been presented by Haines [15].

More than 50 years ago, Kalousek and Adams [4] used endotherms in the vicinity of $500{ }^{\circ} \mathrm{C}$ in DTA to prove the presence of $\mathrm{CH}$ and $\alpha-\mathrm{C}_{2} \mathrm{SH}$ in autoclaved cement-quartz pastes. With increased addition of around $40 \%$ of fine quartz, the presence of large amounts of 1.1-nm tobermorite, indicated 
by an exotherm at a higher temperature $\left(\sim 840^{\circ} \mathrm{C}\right)$, was correlated with the observed greater strength of the product. Their DTA findings were supported by other techniques including X-ray diffraction (XRD). In a later publication [16], Kalousek reported that DTA, in conjunction with chemical analysis, was able to differentiate between phases with different $\mathrm{Ca} / \mathrm{Si}$ ratios made from the same aggregate or between phases with the same $\mathrm{Ca} / \mathrm{Si}$ ratio made from different aggregates.

Cantrill et al. [17] used DTA to study reactions in autoclaved cement-quartz systems with and without additives. Peak heights of principal phases, $\mathrm{CH}, \alpha-\mathrm{C}_{2} \mathrm{SH}, \mathrm{C}-\mathrm{S}-\mathrm{H}(\mathrm{I})$, and $\mathrm{C}-\mathrm{S}-\mathrm{H}(\mathrm{II})$, were used to explain the changes in hydration reaction during autoclaving. In a later publication, Cantrill et al. [18] explained the effect of gibbsite addition on hydrothermal cement-quartz reaction, where the height of the dehydroxylation endotherm between 265 and $285^{\circ} \mathrm{C}$ was plotted as a function of gibbsite addition to estimate the amount of unreacted gibbsite. Following a similar investigation on the effect of kaolin and metakaolin addition, Ray et al. [19] concluded, based on the relative heights of an exotherm at $\sim 940{ }^{\circ} \mathrm{C}$, that addition of kaolin accelerated the formation of hydrogarnet compared with that of metakaolin.

In the study of the cement hydration reactions, simultaneous TG-DTA and TG-DSC are the most frequently used thermal techniques because simultaneous thermal methods are able to provide complementary information and differentiation of overlapping thermal events. An example of the usefulness of the simultaneous thermal technique is the determination of total amount of both crystalline and amorphous variety of calcium hydroxide $(\mathrm{CH})$ during the hydration of Portland cement. While XRD can provide an accurate determination of crystalline $\mathrm{CH}$ present in a sample, it fails to include the amorphous variety. Simultaneous TG-DTA has been known to provide the most reliable estimation of total $\mathrm{CH}$ [20]. Klimesch and Ray [21] recommended a method for achieving consistency in obtaining TG-DTA data since variations, not due to the actual specimen being analyzed, could produce significant differences in results. Their suggested method, which employs a two-point rotation for DT curves using computer software and an appropriate choice of analytical parameters, allows the removal of baseline slope from the experimental data, thus providing a logical basis for subsequent data analysis.

Mitsuda et al. [22] employed TG-DTA to illustrate the thermal behavior of hydrothermally prepared $\mathrm{C}-\mathrm{S}-\mathrm{H}$. They reported that the $\mathrm{Ca} / \mathrm{Si}$ ratio played an important part in the shift and number of exotherm related to the phase transformations at temperatures between 800 and $900{ }^{\circ} \mathrm{C}$. Klimesch [6] found TG-DTA to be particularly valuable in detecting the onset of Al-tobermorite formation and differentiating between Al-tobermorite and (Al)-C-S-H(I) in hydrothermally cured samples containing either kaolin or metakaolin.

In a relevant study using TG-DTA, in conjunction with XRD and NMR, of the mechanochemistry of hydrothermally prepared Al-free and Al-tobermorite, Sasaki et al. [23] noted that for both types of tobermorite, the endothermic peak $\sim 200{ }^{\circ} \mathrm{C}$ shifted to lower temperatures with increasing mechanochemical treatment time.

TG-DSC investigation of the thermal dehydration of 1.4-nm tobermorite by Yu and Kirkpatrick [24] revealed a series of dehydration steps attributed to relevant phase transformations. Using a combination of TG-DSC, XRD, and NMR, the authors provided valuable structural information on tobermorite. Klimesch and Ray [25], used DSC to study the effect of finely ground construction and demolition $(C \& D)$ waste rich in clay brick on the formation of 1.1-nm tobermorite in autoclaved Portland cement-quartz mixtures and reported that addition of up to $41.25 \%$ by mass of the waste enhanced the formation of Al-tobermorite. They also found that DSC provided more definitive proof of the presence of (Al)-C-S-H than XRD.

Using a combination of DTA, TG, XRD, and chemical analysis, Marchese et al. [26] characterized hydrothermally synthesized hydrogarnets, and reported a linear relationship between the endothermic peak temperatures $\sim 315{ }^{\circ} \mathrm{C}$ and Si-hydrogarnet composition. More recently, Klimesch and Ray [27], in a comparative study of different aluminous additives, established that the endotherm temperature decreases with decreasing Si-hydrogarnet amount and increases with Si content. 
Klimesch and Ray [7-9,28] carried out a detailed investigation on the evolution of phase developments with reaction time in the hydrothermally cured $\mathrm{CaO}-\mathrm{Al}_{2} \mathrm{O}_{3}-\mathrm{SiO}_{2}-\mathrm{H}_{2} \mathrm{O}$ system, where they used bulk compositions relevant to commercial products. The authors conclusively established that, contrary to previously accepted theory, hydrogarnet was always one of the first phases formed and invariably appeared before Al-tobermorite. They found TG-DTA, in particular, to be an invaluable technique to detect the presence of trace amounts of hydrogarnet and to monitor both its onset and breakdown during the hydrothermal treatment. The authors provided supporting evidence from XRD, NMR, scanning electron microscopy (SEM), and wet chemical analysis.

It should be noted that while a derivative thermogravimetric analysis (DTG) may give better resolution of peaks of complex mass than the equivalent dynamic TG, it does not necessarily allow sufficient time for completion of reaction. Thus, DTG peaks are often not sharp. El Jazairi and Illston [29] suggested a semi-isothermal approach for phase analysis in Portland cement paste since it allowed an improved separation of overlapping peaks. Klimesch and Ray [30] reported that the semi-isothermal method of El-Jazairi and Illston was highly successful in separating endothermic peaks in both low- and high-temperature regions for evaluating extent of carbonation of hydrothermally cured cement quartz pastes. Klimesch and Ray [31] and Klimesch [6] reported that second derivative DT curves yielded more detailed information than the corresponding DT curves, especially in the high temperature region of 800 to $1100{ }^{\circ} \mathrm{C}$ for hydrothermally cured cement-quartz-metakaolin pastes and lime-quartz slurries and autoclaved cement-based building products.

\section{CONCLUSIONS}

Hydrothermal curing is a proven and widely used process for cement-based building products. The process is capable of handling waste materials such as fly-ash and blast furnace slag and solid mine refuse. It is highly likely that many of the new-generation starting materials, especially renewable resources, alternative binding materials to Portland cement and novel approaches to blending of cements using a variety of nontraditional pozzolanas will be used to manufacture building materials of the future. Inevitably, the hydrothermal curing process will undergo modifications if it is to remain as one of the preferred methods for the production of cement-based building materials.

Current research at the University of Technology, Sydney, is involved with the development of sustainable building materials based on the $\mathrm{CaO}-\mathrm{Al}_{2} \mathrm{O}_{3}-\mathrm{SiO}_{2}-\mathrm{H}_{2} \mathrm{O}$ system. The idea of utilizing $\mathrm{C} \& \mathrm{D}$ waste of high aluminosilicate content is relatively new. Clay brick fines generated during the production of recycled aggregates from $C \& D$ waste have been shown to exhibit high pozzolanic activity under ambient conditions [32]. Since autoclaving has the ability to enhance chemical reactivity, wastes containing a substantial proportion of clay brick fines could be a promising avenue for selective and partial removal of both naturally occurring raw materials such as quartz sand and Portland cement, the traditional binding material. As mentioned earlier, DSC has proved to be a valuable technique in detecting the formation of Al-tobermorite in autoclaved cement-quartz mixtures with additions of up to $41.25 \%$ by a mass of ground $\mathrm{C} \& \mathrm{D}$ waste rich in clay brick.

A number of alternatives to Portland cement are known, although literature on their use in hydrothermally cured products is lacking. The category of energy-efficient cements, which may offer attractive alternatives to Portland cement, includes sulfoaluminate-belite (SAB) cements, geopolymers, silica-water-suspension-binders (SWSBs). Janotka and coworkers have reported promising results from their experimental investigation of blended SABs [33]. Durie and Samarin have remarked that geopolymers, which were commercially introduced in parts of Europe and the United States in the 1980s, are suitable for general construction purposes, and their production results in relatively minor amounts of $\mathrm{CO}_{2}$ emission compared with that of Portland cement. In this respect, SWSBs also offer an attractive alternative to Portland cement. Potentially, in the hydrothermal curing process, these alternative inorganic binders are natural successors to Portland cement-based building products. 
The future? With a constant search for materials that require less energy to be produced and/or recycled, coupled with the proven advantages of hydrothermal treatment to manufacture sustainable building products, the prospect of calcium aluminosilcate-based materials must be exciting for both researchers and manufacturers. The ability of TA to resolve phase characterization in complex reactions, especially when used in combination with complementary analytical techniques, will ensure a challenging future for this relatively simple but sophisticated method of analysis.

\section{REFERENCES}

1. H. F. W. Taylor. Cement Chemistry, Academic Press, London (1997).

2. G. L. Kalousek. Proc. $5^{\text {th }}$ Intern. Symp. Chemistry of Cements 3, 523-537.

3. J. Lutter. Advances in Autoclaved Aerated Concrete, F. W. Wittmann (Ed.), pp. 277-282, A. A. Balkema, Rotterdam (1992).

4. G. L. Kalousek and M. Adams. J. Am. Concr. Inst. 23, 77-90 (1951).

5. G. L. Kalousek. J. Am. Ceram. Soc. 40, 74-80 (1957).

6. D. S. Klimesch. Ph.D. thesis, p. 555, University of Technology, Sydney (1999).

7. A. Ray, E. R. Cantrill, M. G. Stevens, L. Aldridge. Thermochim. Acta 250, 189-194 (1995).

8. J. M. Coldrey and M. J. Purton. J. Appl. Chem. 18, 353 (1968).

9. D. S. Klimesch and A. S. Ray. Adv. Cem. Res. 11, 179-185 (1999).

10. V. S. Ramachandran. Applications of Differential Thermal Analysis in Cement Chemistry, Chemical Pub., New York (1969).

11. R. C. Mackenzie. Differential Thermal Analysis, Academic Press, London (1970).

12. L. Ben-Dor. Advances in Cement Technology, Pergamon, Exeter, UK (1983).

13. J. I. Bhatty. Thermochim. Acta 189, 313-318 (1991).

14. D. S. Klimesch and A. S. Ray. In Advances in Cement and Concrete Technology, S. Ghosh (Ed.) (2002). In press.

15. P. J. Haines. Thermal Methods of Analysis, Blackie, London (1995).

16. G. L. Kalousek. J. Am. Concr. Inst. 26, 989-1011 (1955).

17. E. R. Cantrill, M. G. Stevens, L. P. Aldridge. In $9^{\text {th }}$ ICCC, Vol. 1, 145-148 (1992).

18. E. R. Cantrill, M. G. Stevens, A. S. Ray, L. P. Aldridge. Thermochim. Acta 224, 241-246, (1993).

19. A. S. Ray, E. R. Cantrill, M. G. Stevens, L. P. Aldridge. Thermochim. Acta 250, 189-193 (1995).

20. H. G. Midgely. Cem. Concr. Res. 9, 77-80 (1979).

21. D. S. Klimesch and A. S. Ray. Thermochim. Acta 289, 41-54 (1996).

22. T. Mitsuda, S. Kobayakawa, H. Toraya. In $8^{\text {th }}$ ICCC, Vol. 3, 173-178 (1986).

23. K. Sasaki, T. Mitsuda, H. Ishida. J. Am. Ceram. Soc. 79, 1596 (1996).

24. P. Yu and R. J. Kirkpatrick. Concr. Sci. Eng. 1, 185 (1999).

25. D. S. Klimesch, A. S. Ray, J.-P. Guerbois. Thermochim. Acta 389, 195-198 (2002).

26. B. Marchese, G. Mascolo, R. Sersale. J. Am. Cer. Soc. 55, 146-148 (1972).

27. D. S. Klimesch and A. S. Ray. J. Therm. Anal. Calor. 56, 27-31 (1999).

28. D. S. Klimesch and A. S. Ray. Thermochim. Acta 316, 149-154 (1998).

29. B. El-Jazairi and J. M. Illston. Cem. Concr. Res. 7, 247-252 (1977).

30. D. S. Klimesch and A. S. Ray. Thermochim. Acta 306, 159-166 (1997).

31. D. S. Klimesch and A. S. Ray. Thermochim. Acta 307, 167-173 (1997).

32. S. Wild, A. Gailius, H. Hansen, L. Pederson, J. Szwabowski. Copernicus Research Project, European Commission, Brussels (1998).

33. I. Janotka and L. Krajci. Adv. Cem. Res. 11, 35-41 (1999). 